\title{
Chapter 6 \\ Creating Order from (Potential) Chaos: Embedding Employability with the Griffith Sciences PLUS Program
}

Gayle Brent

\begin{abstract}
PLUS (Professional Learning for University Students) provides a platform for a scaffolded, student life-cycle approach to career learning designed to create strong connections between a student's university work, life experiences and their future career. The PLUS program emphasises achievable targets for students via a series of 'bite-sized' tasks and activities appropriate for each stage of the student life cycle. In 2016, PLUS was adopted by the Griffith Sciences Group as the platform to increase and improve curricula opportunities for students to develop their transferable and personal skills, contextualised by their discipline, to enhance their overall employability. Development of PLUS as a curricular strategy aligns with the shift in Australian higher education to ensure graduates are 'job capable', with the ability to apply their skills across diverse industries and in a diverse range of roles. This can be achieved by clearly and overtly attaching value to tasks, activities, learning outcomes and assessments that specifically relate to employability, and by providing the opportunity for students to identify, record and reflect on relevant co-curricular and extra-curricular experiences. The program is delivered via a series of inter-related worksheets and templates in an online personal learning platform that enables staff and students the opportunity to create links between diverse learning experiences, whilst simultaneously ensuring the flexibility for students to adapt their work to suit multiple purposes.
\end{abstract}

Keywords Employability $\cdot \mathrm{STEM} \cdot$ Higher education $\cdot$ ePortfolio $\cdot$ PebblePad

\footnotetext{
G. Brent $(\varangle)$

Office of the PVC (Griffith Sciences), Griffith University, Southport, Australia

e-mail: g.brent@griffith.edu.au
} 


\subsection{Introduction}

\subsubsection{Employability in Higher Education}

It is widely recognised that the 'future of work' is changing. Graduates can anticipate working in up to 17 careers with the emphasis on fluid and flexible approaches to work, rather than on rigidly defined, 'traditional' career pathways (Foundation for Young Australians, 2017). The impact for higher education institutions (HEI) is the very real need to equip students, not only with foundational disciplinary knowledge, but with the ability to successfully adapt their skills to changing circumstances and to apply their skills in unfamiliar contexts (Wharton \& Horrocks, 2015; Stephenson, 1998, cited in Yorke, 2006). It is vital to acknowledge that the role of HEIs is not to produce 'work-ready' graduates, although this terminology is often used interchangeably with the arguably more accurate term 'job capable'. Finkel (2016) emphasises that university graduates should not be expected to be robots who will simply slot into place in the workplace. Lauder (2011, cited in Jackson 2014) likewise challenges the notion of graduates who are 'plug in and play'. Instead, they make the strong point that the role of the HEI is to help prepare graduates for lifelong learning and work. Given the nonlinear pathways expected in the future, a graduate is who is prepared for lifelong learning and work will also have the requisite skills to manage their career, and thus, career management becomes a critical element in employability-based learning.

\subsubsection{Employability in STEM}

There are strong links between the 'unknown' future of work and the need for graduates to have transferable skills that can be readily adapted to jobs and technologies that do not exist yet (Queensland Government Department of Education, Training and the Arts, n.d.). This is particularly relevant for graduates of STEM disciplines, given the expectation that these graduates will have a significant role to play in Australia's potential for innovation. A paper delivered by PricewaterhouseCoopers (2015) reported that $75 \%$ of the fastest growing occupations require STEM skills. They also reported that the skills developed within STEM studies are becoming increasingly critical in a diverse range of roles and industries (not necessarily 'traditional' STEM roles).

The challenge for educators within STEM disciplines is the current perception of a mismatch between the skills STEM graduates have and the skills employers of these graduates are seeking. Reports from the Office of the Chief Scientist (Prinsley \& Baranyai, 2015) and the Australian Industry Group (2015) both highlight this mismatch, with identified barriers including the lack of alignment between the transferable skills employers want and students' understanding of their skills, the 'lack of employability skills' and the 'lack of applicants with STEM skills'. The latter, in particular, is of serious concern for HE institutions and STEM educators. A key question 
to be addressed is whether or not students (and graduates) really lack STEM skills, or if they simply lack the ability to identify and articulate their skills, and if they likewise lack the creativity to understand how their skills might transfer and become applicable in diverse contexts. Hinchliffe and Jolly (2011, cited in Thompson, Clark, Walker, \& Whyatt, 2013) comment that employers are limited to assessing potential, not performance, as the latter only becomes evident after employment. It is therefore essential that students (and graduates) have enough opportunity to reflect on their learning so they can competently and confidently articulate their capabilities to demonstrate their potential for success.

\subsubsection{Barriers for Developing Student/Graduate Employability}

There are multiple barriers for higher education practitioners seeking to help students develop their employability awareness and skills and/or who seek to guide students through a process of career development learning. While the scope of this chapter does not allow for a full review of all of these barriers, three are identified as particularly relevant.

The first is the very real challenge for students to 'fit everything in'. We recognise that students are generally very busy people with multiple priorities and competing demands on their time, and yet many employability programs are still extra-curricular in nature. The second is the notion that we (academics, careers staff, etc.) often advise students of the many opportunities that exist to help them develop their skills and knowledge and their awareness of career development learning, but we do not necessarily provide them with a clear structure and/or timelines for when, why and how to engage in particular activities; thus, students are forced to make decisions about participation without meaningful guidance. Finally, there is the potential for students to engage with employability-based learning and career development activity in an ad hoc and piecemeal way-that is, they participate in many activities that do not connect to each other in a coherent and progressive way; thus, the value of their participation (what they get from the experience) is potentially negatively impacted.

\subsubsection{Griffith Sciences PLUS}

PLUS (Professional Learning for University Students) is an employability-based program initially developed in 2014 to enhance the experience of Griffith Sciences students and to create strong connections between university work, life experiences and their future career. PLUS provides a platform for a scaffolded, student life-cycle approach to employability-based learning, and it emphasises the need for students to proactively prepare for the transition from student identity to professional iden- 
tity. The PLUS program emphasises achievable targets for students, presented via a coherent series of activities linked to the student life-cycle in the stages proposed by Lizzio (2012): transition in (Explore), transition through (Experience) and transition out (Expand).

PLUS was initially developed as an extra-curricular program (modelled on similar programs offered at many universities in the UK) and was later adopted by the Sciences Group (faculty) as the platform and mechanism to increase, enhance and improve curricula opportunities for students to develop their transferable and personal skills, within the context of their discipline, to enhance their overall employability. PLUS is now offered in both the extra-curricular and curricular formats to try to overcome the challenges to developing students' employability outlined above.

The embedded approach recognises the need to clearly and overtly attach value to tasks, learning outcomes and assessments that specifically relate to employability. This approach has multiple benefits, not least of which is the opportunity to affirm for students that employability and career development activities are important and that they are highly valued by the university and by employers. That said, although the benefits of an embedded strategy are clear, this approach (like the extra-curricular approach) is not without its challenges.

\subsection{Defining Employability}

A universal definition for 'employability' has not been established, and descriptions of employability can vary greatly between scholars. That said, there is general consensus that employability is a complex and multifaceted concept that encompasses discipline knowledge and technical skills, personal qualities and attributes, the ability to reflect, the ability to create or sustain work and the capacity to contribute positively to society (e.g. Kinash et al., 2015; Bennett, Richardson, \& MacKinnon, 2016). Holmes (2001) presents an alternative approach to employability based on the notion of 'graduate identity' aligned to the relevant behaviours and performance required for graduates to be successful at work. The diversity of interpretation between these scholars alone (and there are many more exploring this field) emphasises the need to establish a shared understanding of what is meant by employability at an institutional level. This is further emphasised by Pegg, Waldock, Hendy-Isaac, and Lawton (2012) who advocate for an institution-based approach to employability rather than a 'one-size fits all' model. This approach accommodates the many interpretations of employability and allows for a customised approach that suits a specific cohort of students at a specific institution, rather than a universal approach that may not meet the needs of all students.

Once a shared understanding of what is meant by 'employability' is established, unpacking the concept for 'non-expert' audiences (which include academic staff and students) (Dacre Pool \& Sewell, 2007) becomes essential. In the Griffith Sciences Group (faculty), developing staff (and student) understanding of employability is based on the Career, Academic, Personal (CAP) model proposed by Brent, Sanger, 


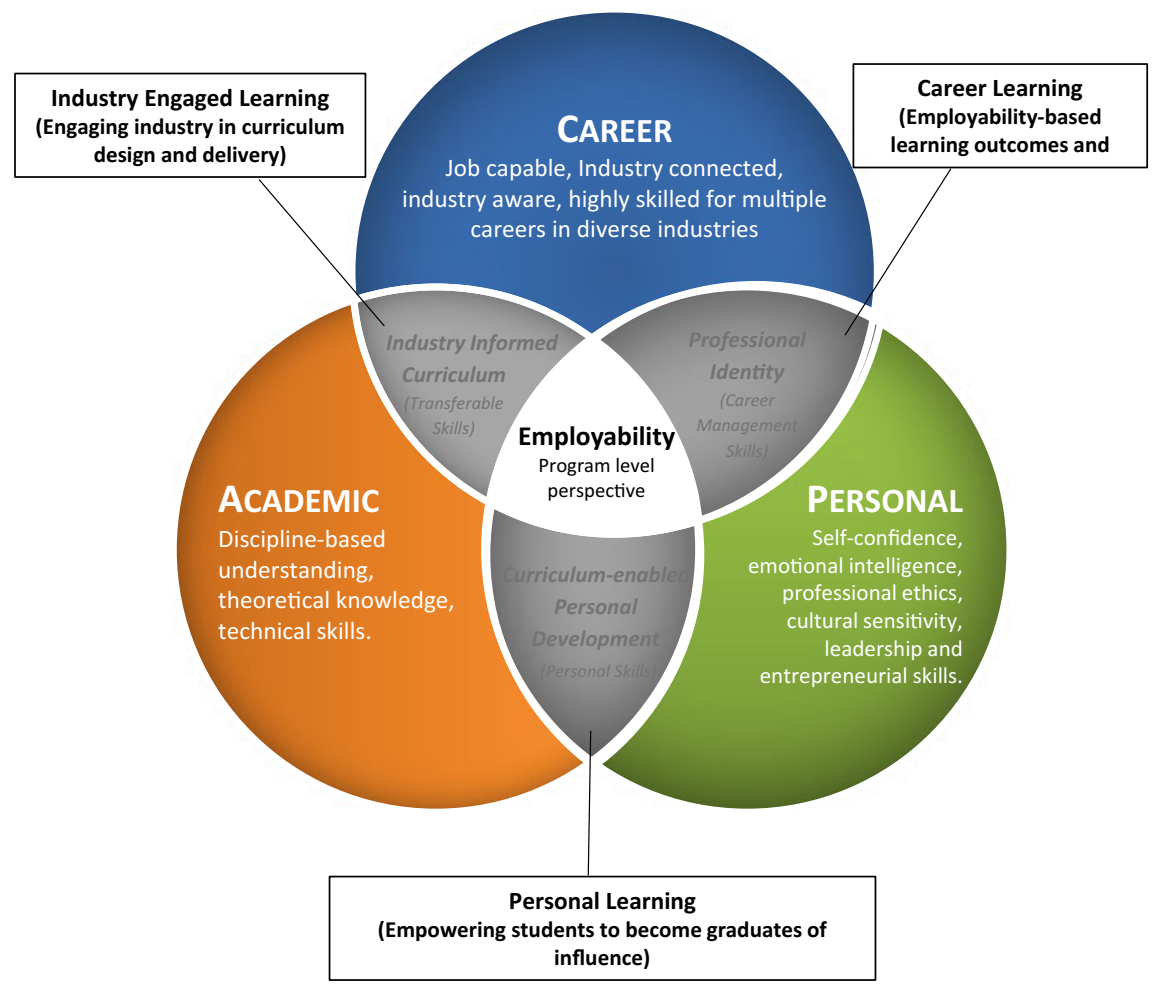

Fig. 6.1 Griffith Sciences Career, Action, Personal (CAP) model for employability

and John (2017), represented in Fig. 6.1. This model addresses each of the basic dimensions outlined above in a visual representation that emphasises the importance of all three areas of student development as equal (Career, Academic and Personal). The model likewise emphasises that developing employability is dependent on all three areas being addressed in an integrated way.

\subsubsection{Employability-Based Learning for Non-experts}

Rich (2016) observes that while academics are well placed to teach employabilitybased learning, they do not necessarily have the requisite knowledge or motivation to do so effectively. Many teaching academics have regular contact with students as a natural course of delivering university courses (subjects). They also create subject-specific and discipline contextualised learning activities and resources for students. Theoretically, this might mean they could easily integrate employabilitybased learning and assessments within the discipline. However, Rich's (2016) obser- 
vation regarding knowledge and motivation highlights that this is often not the case. Rogers and colleagues (2016) likewise identify barriers to employability-based learning given many academics have worked in academia for their entire career and are therefore not experts when it comes to employability. This aligns with the model of employability proposed by Dacre Pool and Sewell (2007) which was intentionally developed for a non-expert audience, including (some) academic staff, students and parents.

The inherent (although often overlooked or underplayed) complexity of employability, coupled with an understanding that academic staff may not feel equipped to deliver employability-based learning, was fundamental to the adoption of the PLUS program as a curricular strategy to address student employability in the Sciences Group.

With the imperative to embed employability-based learning in curricula established, the original PLUS program was revised to align with the three core dimensions of employability presented in the CAP model (Brent et al., 2017). This approach ensures both staff and students can easily align the PLUS tasks to relevant developmental areas in the context of employability.

Activities in the PLUS program rarely sit in just one of these 'categories' of employability. Instead, they are interlinked, crossing over to highlight the relationships between academic skills/career management, career management/personal attributes and personal attributes/academic skills. These can broadly be interpreted as industry-based learning, personal learning and career learning. This practical interpretation of employability, combined with the student life-cycle approach in the PLUS program, has resulted in the creation of an employability 'toolkit' (individual worksheets and templates developed in PebblePad) that can be readily contextualised to a discipline, integrated into targeted courses, and which promote a program-level approach to employability.

\subsubsection{Creating Equitable Opportunities}

Extra-curricular employability achievement programs (like extra-curricular PLUS) have the potential to help students develop their awareness of the need to be strategic about extra-curricular activity to help them make informed choices that will not detract from their academic performance and will give them the greatest potential to differentiate themselves in the competitive graduate job market.

Evidence suggests a structured program to recognise student involvement in, and contribution to extra-curricular activities has a positive impact on the student experience and development of capability (Muldoon, 2009). Muldoon (2009) explored this concept in relation to part-time work. Results in that study indicated students did not work solely to complete an extra-curricular award program, but they did value the institutional recognition of their effort in terms of the future employability. An extra-curricular employability achievement scheme can empower students to more readily recognise the value of the involvement in extra-curricular activity 
which is highly desirable given employers emphasise the value of diverse experiences. Greenbank (2014) refers to this as 'personal capital' and he emphasises that extra-curricular experiences are one way students can demonstrate and evidence their skills and capabilities in a way that is attractive to employers.

An important consideration for universities, however, is that not all students have equal opportunity to participate in extra-curricular programs. Rich (2016) has noted the impact of initiatives designed to increase the participation of lower socioeconomic students in university study. In Australia, the Higher Education Participation and Partnerships Program (HEPPP) is one such example. This type of initiative has expanded the potential for university students to need to balance full or parttime work, caring responsibilities, financial obligations and the general business of 'life' alongside their university study. While there may therefore be a 'place' for extra-curricular employability programs, there is likewise a very strong case for the 'basics' of employability to be embedded and integrated within degree programs to create equal opportunity for all students to engage in employability-based learning.

\subsubsection{Limitations of Bolt-On Programs}

Student engagement with activities that are perceived to be 'add-ons' to their core program is invariably hit and miss in terms of attendance and uptake. Many students are time-poor with significant external commitments that demand their attention (e.g. paid work, family commitments). Developing a program of activities that empower students to build strong professional skills in addition to their disciplinary knowledge and attaching a tangible, distinctive 'award' to this program is one potential way to positively impact the student experience and improve their commitment to extra-curricular developmental opportunities. PLUS was initially designed with this purpose in mind and was intended to be an extra-curricular program to aid student retention. The theory was to help students connect with their sense of purpose (why they chose to come to university) and to help them connect with others (make friends) to help them stick with study through some of the inevitable challenges.

PLUS was offered as a pilot program in 2014. In this first iteration, a select group of student leaders were invited to participate in the activities. This included participating in focus group activities to help shape the future versions of the program. Many of these high achieving and motivated students did not complete all activities - an outcome that highlighted the limitations and challenges encountered by many students. That is, they can perceive that it is important and necessary to engage in career development learning early on, and throughout their degree, but they cannot always afford the time to do so in light of competing demands on their time such as university assessment deadlines, the imperative to work, family obligations and student experiences. 


\subsection{Why Embedding Employability Is Essential}

A key factor motivating students to attend university is the potential for them to secure fulfilling work when they graduate (Rich, 2016). It follows that there might be an expectation that students will actively seek to engage in career and professional development throughout their degree because they understand the link between career learning activity and enhancing their graduate potential. Unfortunately, this is manifestly untrue. In fact, there is evidence that the exact opposite is the reality. Rich (2016) summed it up nicely when he commented that the 'awkward reality and the drudgery of needing to secure employment slides down the list of priorities when there is studying to be done, life to be managed and the pleasures of student life to be experienced' (p. 16). He further observes that career management (and by extension, employability) is something very few students engage with before their final year of university. A contributor to this phenomenon may be that many students confuse employment with employability, and it is therefore quite easy to dismiss it until it is really necessary. Rich (2016) advocates an approach that celebrates employability and inspires students to engage in ways that are interesting and enjoyable (we hope the PLUS program is!).

While Rich's sentiment is phrased rather flippantly (it would appear this is done intentionally), a deep issue is nonetheless emphasised in that students (like everyone), need to 'live' first and foremost. The flippancy of 'life to be managed' should not diminish the impact of a student required to juggle work and life to ensure immediate 'survival', while simultaneously engaging in study and striving towards a potential future.

Add to this the challenge of trying to engage students in a 'bolt-on' extra-curricular model for developing employability and additional (significant) challenges emerge. Wingate (2006) suggests that 'bolt-on' strategies are not 'attended by the students who need them the most but by high achieving students who want to enhance their performance further' (p. 458). Her study specifically focuses on study skills programs, and however, many of the challenges and limitations she highlights are equally applicable to extra-curricular career development programs such as the extra-curricular PLUS program.

\subsection{Curriculum-Based Employability Strategies}

Given the inherent challenges that exist for purely extra-curricular programs (inspiring and motivating students to engage with and complete activities; and providing equal opportunity for students to participate) and the expectation that HEIs will (or should) play a role in preparing graduates for life and career success, there was a strong rationale to develop an embedded approach to employability-based learning within the Griffith Sciences Group. While the current short-term measure of success for graduate employability (the Graduate Outcomes Survey) arguably has some 
impact on the momentum to embed employability, the longer term, and arguably more altruistic objective, is to ensure graduates really are prepared for success in the workplace and in life. To meet this objective, the Griffith Sciences Group developed a full and comprehensive approach to student employability including the introduction of relevant pedagogies to promote the development of skills and capabilities valued by employers. The strategy also reflects a student life-cycle approach that recognises the imperative to integrate employability-based learning throughout a degree program. Yorke and Knight (2006) comment that students need time, practice and repetition to judge what they have achieved and to see how to improve. Providing multiple opportunities for students to engage in employability-based learning is therefore critical.

Further incentive to embed EBL is evident in the assertion of Pegg et al., (2012) who emphasise the inter-relatedness of teaching discipline-based content and simultaneously developing key employability skills. They comment that teaching 'one does not preclude the other' (p. 41) and they draw on Barrie's 2009 work to stress that successful models for developing employability are not 'discipline content + generic skills', but are those in which graduate attributes (and employability skills) are contextualised by the disciplines.

An embedded approach addresses multiple factors that may otherwise inhibit the development of students' employability, namely

- the inability or lack of motivation for some students to engage with an extracurricular program;

- the fundamental need for students to scaffold their skills from first to final year and

- the importance of delivering employability-based initiatives in a comprehensive, integrated way within the context of the student's discipline.

\subsection{PLUS Overview}

PLUS was developed as a 'one-stop-shop' to help students understand the need to engage in ongoing career development learning and to help them identify what they should be doing and when they should be doing it. Figure 6.2 provides a visual overview of the program, highlight compulsory activity (darker boxes) in the three achievement levels.

PLUS is presented in student-friendly language, using a points-based system to motivate students to engage with a variety of activities to reach particular levels of achievement. It provides a scaffolded approach to career learning and emphasises the need for students to be consistently proactive to prepare for the transition from student to professional. Students are introduced to activities in the areas of 'Explore Your Options', 'Get Real Experience' and 'Expand Your Prospects'. The clear structure and 'bite-sized' nature of the steps encourage engagement with employability-based learning, decreasing the likelihood students will simply do nothing because it seems 


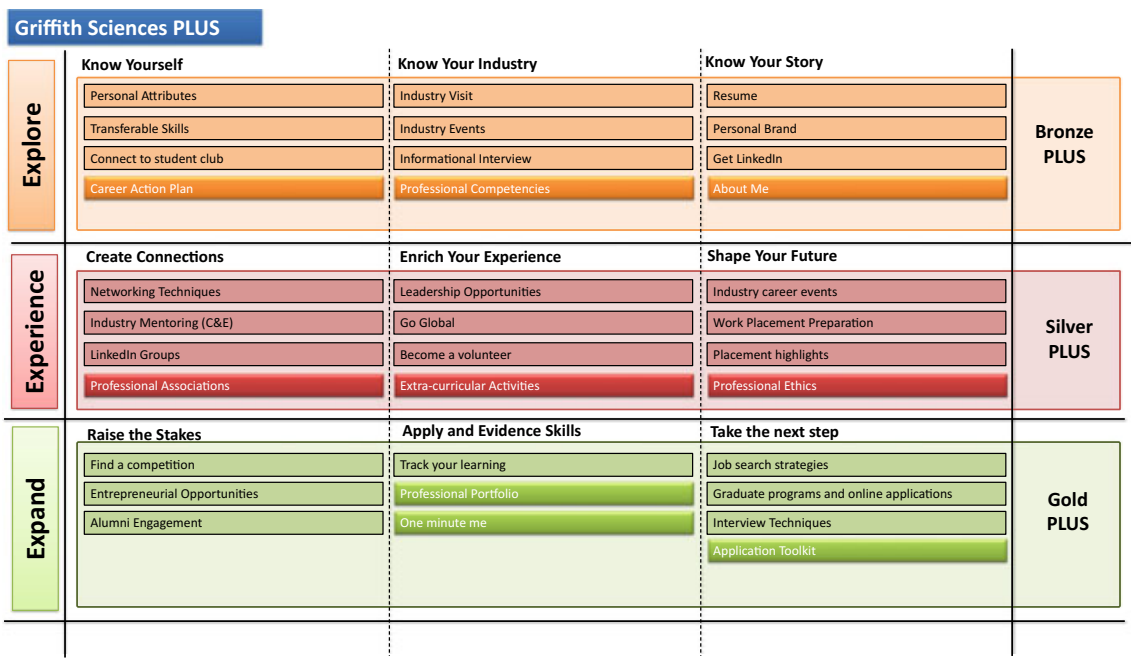

Fig. 6.2 Overview of the Griffith Sciences PLUS program

too overwhelming and they do not know where to start. The 'grouping' of the PLUS activities into the broader areas (including the sub-areas as per Fig. 6.2) ensures students can make strategic choices about which activities to engage in and ensures there is opportunity for them to recognise the links (coherence) between activities. This again aligns with the notion of employability as multifaceted and ensures students have an opportunity to select activities that align with all three dimensions of employability presented in the CAP model.

\subsubsection{PLUS Online (PebblePad)}

PebblePad is an online, personal learning environment introduced to Griffith University at the beginning of 2017 . The portability, accessibility and interactivity of the platform created an opportunity to reinvigorate the original 'information-based' PLUS program and recreate it as a series of short, interactive, online modules. Each module provides students with context and rationale for engaging with an activity that will contribute to their employability. It provides detailed instructional information and provides information-rich resources that allow students to develop their skills and knowledge prior to experience and to record and reflect on their experiences after the event. The modules are visually engaging and feature images, video and links to external resources to create an effective online learning experience for students. Importantly, the functionality of PebblePad has been leveraged to ensure students have frequent opportunities to record their thoughts as they progress through each module. 


\subsection{PLUS Structure-Maximising the PebblePad Advantage}

While simple in concept the PLUS program is actually a detailed and complex suite of resources that initially proved challenging to deliver to students in an interactive and engaging way. Although the technology and features of PebblePad were uniquely suited to the goals of the program, establishing the most effective way to structure the program within PebblePad was still an iterative process that took some months to refine.

One factor contributing to this challenge was that PLUS had already been developed with substantial detail within Griffith's Learning Management System-Blackboard. While some elements of interactivity were included, Blackboard is largely a content management system, so the development of the program in this platform was primarily information-based. Students were provided with the rationale for an activity, directed to a number of resources to help them build their knowledge and then provided with suggestions about how the activity may contribute to an online portfolio to help showcase their experiences. At this stage in the development process, Griffith did not have an institution-wide ePortfolio platform, and students were encouraged to explore web-based options like Wix or Weebly to develop their 'ePortfolio' (or Portfolio website).

In the initial development, a direct transfer of information (including layout and some design features) from Blackboard to PebblePad did take place. However, it quickly became obvious that this approach underutilised the functionality of PebblePad, particularly with respect to the potential for PebblePad to seamlessly integrate content and interactivity to contribute to students' ongoing personal and professional development.

\subsubsection{Creating Order from (Potential) Chaos}

One of the significant advantages of delivering the PLUS program through PebblePad was the opportunity to design a series of resources that work together as the 'whole' PLUS program, and which simultaneously 'stand-alone', ready to be adapted for use in specific disciplines and to support curriculum-based assessment.

The 'stand-alone' approach adopted also caters for the individual tailoring of the PLUS experience in that students have the freedom to select the activities they will complete within the program on an individual basis. To achieve this, the creative potential, diversity and flexibility of PebblePad was maximised to present each aspect of PLUS in its best possible form (see Fig. 6.3). As it currently stands, PLUS is presented as:

- The Griffith Sciences PLUS Portfolio-linked to a public facing short URL. This site provides a short introduction to each activity and access to a registration form. 
Professional Learning for University Students (PLUS)

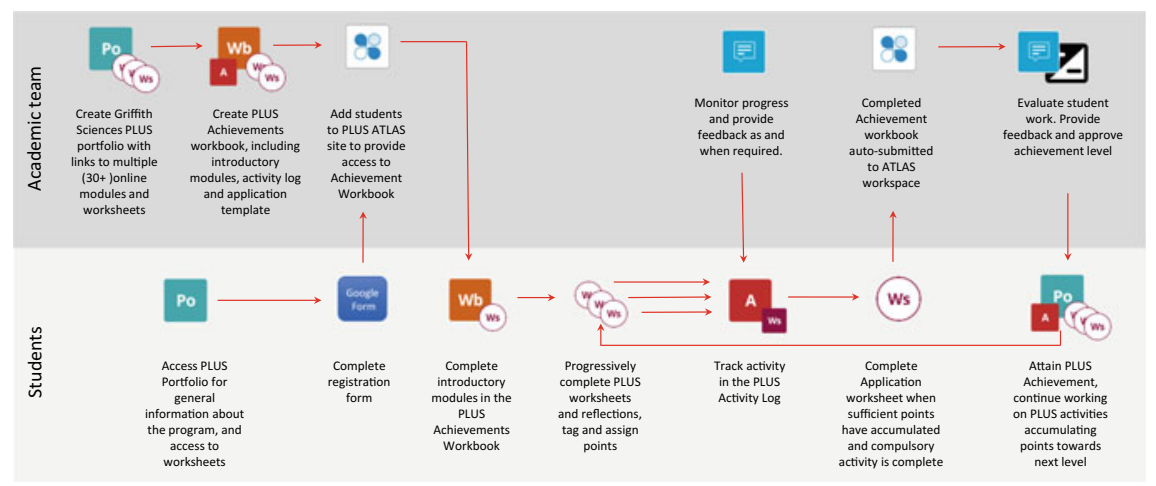

Fig. 6.3 Learning design Griffith Sciences PLUS program

- PLUS Achievements Workbook-the comprehensive PLUS program including introductory modules, links to all activities and worksheets, an activity log and application forms for each achievement level.

- PLUS Templates (worksheets and reflections)_online learning modules with detailed information to guide the student through each activity, with a significant proportion to be completed by the student.

Aspects of these resources and activities are explored in further detail below.

\subsubsection{Introductory Modules}

Students begin the PLUS program by completing four, short introductory modules:

- Intro to Employability

- Intro to Reflection

- Intro to ePortfolio

- Intro to Experiences

These modules are largely content-based, with a few short activities to allow the student to record their thoughts. The introductory modules are largely designed to 'set the scene' for students and to establish why the career development learning is important for them to engage with throughout their degree. The introductory series was intentionally designed as four distinct worksheets (rather than a single workbook) to ensure maximum potential for them to be assimilated into coursebased assessments. That is, when adapting activities from the PLUS program for curriculum-based learning, different introductory modules may be applicable.

In Engineering, for example, students complete the 'Intro to Reflection' and 'Intro to Employability' modules as an integral component of their Professional Com- 
petencies workbook in second year. Completion of this workbook is weighted at $10 \%$ in four courses, across all Engineering disciplines (all second-year Engineering students complete the same assessment). The assessment task includes substantial reflective practice as students are required to reflect on information presented by guest speakers and to assimilate this with their own understanding of employability in the Engineering industry (evidenced by their reflection on how they can demonstrate the Professional and Personal Stage 1 Engineering Competencies).

In Science, first-year students complete the 'Intro to ePortfolio' module as a component of an assessed task to develop an 'About Me' page, which could ultimately become the landing page for an ePortfolio. The About Me task included in this $(5 \%)$ assessment is also drawn directly from the PLUS 'About Me' activity (so students can accumulate points towards PLUS by completing this activity).

The way the worksheets are structured ensures students complete only one version of the activity. The worksheets are pre-tagged with the 'PLUS' or 'Bronze PLUS' tag, even when delivered via a course-based assessment. This means when the student 'turns on' the search function in their activity log, the worksheet is automatically included in the list of completed activities for PLUS.

\subsubsection{Why 'Intro to Reflection?'}

Yorke (2006) highlights the importance of including self-reflection in institutional schemes aiming to increase employability. A study of students participating in an extra-curricular program at the University of Lancaster provides insight into this observation. Thompson et al. (2013) interviewed Lancaster-Award holder graduates to determine the value of their participation in the award program. Those interviewed indicated that although the award added some value to their curriculum vitae, and they were aware of its potential benefits when applying for graduate roles, the true value in the program lay with the requirement for self-reflection. This was apparent to the award holders, but not as apparent to graduates who had high participation in extra-curricular activities, but were not enrolled in the Award. It was recognised that participation in the Lancaster Award would not contribute significantly to the development of a particular skill, but that the reflective practice associated with the Award allowed graduates to better understand and articulate their skills and they could then communicate these with more confidence in job interviews (Thompson et al., 2013). Monks, Conway, and Dhuigneain (2006) also commented that the process of professional development planning (PDP) benefits employability if self-reflection is included because it facilitates the identification of explicit transferable skills. They highlight the importance of reflection, not just engagement, to realise the true benefits of participation in extra-curricular activity to enhance employability.

Reflection is a key component of the PLUS program, beginning with the introductory module 'Intro to Reflection' and scaffolding from this throughout each individual online module. The majority of curricular employability tasks also have an intrinsic element of reflection. Students are required to apply a reflective framework to inter- 
pret and explain their experiences (relative to an activity) or to provide evidence to demonstrate their skills and capabilities.

\subsubsection{Why 'Intro to ePortfolio'?}

The 'Intro to ePortfolio' module is intended to introduce the concept of an ePortfolio to students and to highlight the various ways an online collection of their work may be useful to them. The focus in this module is on establishing the purpose of an ePortfolio, with an emphasis on students creating a learning or process ePortfolio in the first instance, with the option to draw from the artefacts they create throughout their degree to create a showcase ePortfolio at a later time if they choose. This concept is based on Barrett's (2010) work on 'balancing the two faces of ePortfolios'. Her work centres on the process ePortfolio-portfolio as a workspace, formative assessment for learning, immediate reflection - and relationship between the process ePortfolio and the product ePortfolio-portfolio as a showcase, evaluation of learning, retrospective reflection. Barret's work helps students to define and reconcile the way to the two aspects of ePortfolio work together to enhance both their learning and their employability.

Differentiating the two 'faces' of ePortfolio is essential to help students understand and truly benefit from their access to PebblePad, not only within the PLUS program, but throughout their degree at Griffith. If students can truly perceive advantages of creating a learning ePortfolio (tracking, recording and reflecting on their progress) they will ultimately create a rich resource of artefacts they can draw from to create a showcase portfolio, or simply to draw from to help them understand and articulate their skills (for example, on LinkedIn, in job application materials, at job interviews and ultimately in the workplace).

\subsubsection{Why an Activity Log?}

Motivating students to engage with career learning and personal/professional development activities can be extremely challenging (Rich, 2016). First, you need to get them interested, and then, you need to keep them interested. Our experience with the extra-curricular PLUS program is an excellent example of this challenge in motion. While many of the highly engaged students in the pilot program in 2014 (PASS leaders, student mentors, student club committee leaders, etc.) had 'light bulb' moments where they discovered the wide variety of things they could do to enhance their employability, many of them were simply unable (or unmotivated) to produce all of the required outcomes to complete the program. As previously noted, this is due in large part to the competing demands on the students' time, coupled with the sense of 'urgency' to attend to tasks that have an immediate impact (e.g. meeting university 
deadlines, earning money) as opposed to those that have a 'vague' future impact (e.g. professional development and career management).

The introduction of PebblePad at Griffith, combined with the success of many game-based learning activities (where students collect points to progress through levels and/or achieve milestones and unlock rewards) (Johnson, Adams Becker, Estrada, \& Freeman, 2014), presented a potential way to address this issue. While it is not a new or novel approach by any means, the introduction of point-based tracking in the PLUS program has the potential to contribute to the student's motivation to participate in activities. This is particularly true if they are able to accumulate some points within the normal course of their study-by completing assessments in class. This is explored further below.

Points for the PLUS program are tracked via an Activity Log in PebblePad based on the search criteria of the PLUS tags (Bronze PLUS, Silver PLUS, Gold PLUS). All PLUS templates are pre-labelled with the appropriate tag, although students do have the flexibility to apply 'Silver' or 'Gold' tags to earlier activities if they wish to have them contribute to the higher levels of achievement (if they have not already been used to accumulate points).

Students are required to enter the points value themselves, as they complete the template. The points allocated to an activity are indicated in both the short description in the PLUS Achievements workbook and in the template itself (including a visual instruction on how to add points in the template). This is usually between 10 and 20 points, although some time-intensive activities may have a higher points value. Activities that have been deemed 'essential' generally have a higher points value even if the activity is not necessarily time intensive. In the Bronze PLUS level, for example, the Career Action Plan attracts 15 points, although it is effectively an online module that students can readily complete within an hour or two. The Career Action Plan is critical for all students in terms of developing their employability, as it provides an opportunity for them to explore career paths (defined or aspirational), to develop awareness of the required skills and capabilities, to identify any additional qualifications or certifications they may need to pursue and to map tangible steps they intend to take in the short term and in the longer term to achieve their goals.

A nested activity log approach was initially implemented with the intention for students to clearly see the accumulation of points in each level of achievement, with an overall points target set to reflect the required points to achieve Gold PLUS. Ultimately, however, this nested approach proved problematic as students would have been required to save the Activity Log and place it into a 'place holder' page in the workbook. The advantage of the nested approach was not significant enough to justify the added complexity for students, and a single activity log has therefore now been implemented.

In this model, the Activity Log is already available to the student in the PLUS Achievements workbook. To activate their points tracking, they simply need to 'turn on' the search, and all templates tagged with a PLUS tag will be recorded against the points total.

As students progress through each level and accumulate 80 points in Bronze, 160 points (total) in Silver and 240 points (total) in Gold, they unlock a variety 
of rewards that directly relate to the goals and objectives of the PLUS program (to enhance student employability). For example, at the Bronze level students will receive a recommendation from the PLUS coordinator on LinkedIn; at Silver level, they receive invitations to attend exclusive professional development events; and at Gold level they are eligible to receive a letter of commendation (with respect to their personal and professional development) from the Dean Learning and Teaching (Griffith Sciences). These rewards are intended to continue to motivate and inspire students to engage with the PLUS activities.

In the very near future (in line with Griffith's move to adopt digital badging), it is anticipated students who complete PLUS will be eligible to receive digital badges in a number of distinct categories (e.g. 'Industry Engagement' or 'Personal Development'). In addition, students may be eligible to receive an overall microcredential in the area of Professional Learning in STEM if they achieve all three levels of Achievement (Bronze, Silver and Gold).

\subsubsection{Hidden Hints}

PLUS is ultimately a learning tool with a student-centred approach to developing employability (and employability awareness). In this context, this means there is a very real intention to ensure the activities within PLUS are developmentally and practicably useful for students as they continue to develop their professional identity and progress towards the transition from university to work (or further study). With this as a core feature of the program, it was essential to ensure students engaging with the online modules would be able to create artefacts that are both useful and usable.

The 'hidden hint' functionally within PebblePad has been applied to achieve this. This feature-deselecting 'include hint block on asset view'-is crucial to creating an asset (i.e. artefact) students can use and share that only reflects the information they have entered. That is, while providing instructional information is vital to the development of the students' knowledge and understanding of employability at the time they complete the worksheet, there is no advantage to them to present this information to others, or even to have to 'wade through it' themselves to revisit the information they have entered. Instead, by applying the 'hidden hint' approach, once they have completed a module, all extraneous information is removed, and the student is left with a 'clean' artefact they can use in multiple situations.

\subsection{Adapting PLUS Modules for Assessment}

A significant advantage of the PLUS structure (individual templates within PebblePad) is the ability to easily adapt each module to align with assessment tasks embedded throughout programs in the Griffith Sciences Group. Individual versions 
of the PLUS program (still under development) are aligned to the disciplines in the Sciences Group:

- Architecture PLUS

- Aviation PLUS

- Engineering PLUS

- Environment PLUS

- IT PLUS

- Planning PLUS

- Science PLUS

Where there are no discipline-specific assessments, students can access the 'generic' (and yet highly detailed!) version of the template. As noted previously, they will complete the activity and assign points to their work so the activity contributes to the accumulation of overall points towards the three achievement levels (Bronze, Silver and Gold). Where there are discipline-specific assessments, students will access these for assessment in targeted courses. The templates are adapted to align to the learning outcomes for specific courses, detailed information about the assessment task is added, and the interactive marking rubric feature of the PebblePad is leveraged to provide an opportunity for students to receive substantial feedback on their work. Within the assessment workbook students receive detailed instruction about how to add the PLUS tag (if it is not already added) and how to assign the appropriate points for the extra-curricular PLUS program.

Structuring PLUS in this way has resulted in a unique approach to employabilitybased learning that encompasses the best of both the extra-curricular opportunities and curricula learning. Students are guided to recognise and create connections between discipline and course-based employability learning and can easily identify complementary, extra-curricular activity they can undertake themselves to extend and enhance their employability. The accumulation of points through work they would have completed as a fundamental component of their course work can potentially inspire students to do 'just a bit more' to continue to enhance their employability and qualify for the PLUS achievement levels and the associated rewards. In this way, the PLUS program is unique amongst a suite of similar programs that are either solely extra-curricular in nature, or which are solely curricular in nature.

\subsection{Impact of the PLUS Program}

Given the ongoing development (and redevelopment) of the PLUS program since its inception in 2014, a formal evaluation has not taken place at this stage. That said, informal evaluation regarding the impact has now been integrated into the program itself via a series of questions about student engagement with and understanding of their developing employability, a checklist of what they have in their 'career toolkit' and a checklist of the types of career learning activities they have undertaken. This short questionnaire is included at the start of the program and is repeated each time 
the student applies for an achievement level. In time, the sophisticated reporting functionality available in the PebblePad submission space (ATLAS) will allow student development to be tracked as they progress through the PLUS activities.

In the absence of formal evaluation, there are still indications that PLUS has had a positive impact on those who have engaged with it. PLUS was utilised as the platform to enable a program-wide approach to employability in the Bachelor of Engineering and the Graduate Diploma of Clinical Physiology at Griffith University. The integration of PLUS into both programs supports the claim above that PLUS comprises a uniquely flexible series of templates that can readily be adapted for diverse disciplines. The embedded approach in Engineering alone has resulted in approximately 900 students and some 12 academics who are actively engaged in EBL.

Feedback from students about the extra-curricular and the curricular PLUS program has been consistently positive since its introduction in 2014, and there is anecdotal evidence the program has a positive impact on students' confidence to transition from university to a graduate role. A sample of student testimonials is included below to give an indication of the impact on student awareness of career learning and their motivation to participate in the program.

"In regards to the job interview...I couldn't have progressed so far without my polished resume and would not have even got my foot in the door if it were not for my professional network - both things that I would not have without the PLUS program."-Final Year Science Student

"The PLUS workbook is amazing."-3rd year Engineering Student

"I found the activities in the PLUS program helpful and they made me think about my employability in ways I hadn't considered before."-2nd year Environment Student

"PLUS provided me with wonderful opportunities and I have learnt so much about the real world."-Graduating Honours student, Bachelor of Science

"Thank-you again for the studio lecturers and the feedback with the PLUS program. It has been invaluable moving forward."-Final Year Architecture Student

"Overall, my experience with the PLUS and ePortfolio program was one that was very valuable and rewarding. I now feel much more aware of my skills and attributes as a soonto-be professional in the workforce."-Graduate Diploma of Clinical Physiology Student

\subsection{Conclusion}

This chapter outlined the extra-curricular development and implementation of the PLUS program in the Griffith Sciences Group, and the evolution of the program to become the platform on which embedded employability-based learning is based.

PLUS is a student-friendly program designed to help students make sense of career learning and to inspire them to undertake continuous, small activities (and to reflect on their experiences) to engage in personal and professional development throughout their degree. Alignment of activities in the program to the student lifecycle (transition in, through and out), and the emphasis on tangible activities related 
to specific employability-based learning objectives made PLUS an obvious choice to develop curricular strategies to address student employability. A curricular (embedded) approach aligns with increasing recognition that higher education institutions have a significant role to play to ensure graduates are prepared to navigate a future career in an evolving global marketplace.

The advantages of PLUS as a platform from which to develop context-specific employability-based learning opportunities are that it provides a uniquely studentcentred take on 'breaking down' employability that allows students the time and opportunity to scaffold their skills across the course of their degree. Each individual PLUS activity can be adapted to suit a specific course with reference to the practical framework and associated resources that empower academic staff to understand, embed and assess employability. This approach is enabled by the functionality of PebblePad as the platform via which all PLUS activities are delivered.

The opportunity for all students to fully engage with a diverse range of experiences that contribute to their employability is also fundamental to its success. This acknowledges that students experience learning (and development of skills and capabilities) within the university setting, within the community (volunteering, sporting, global opportunities etc.) and through industry engagement. It also allows a comprehensive view of employability and that extends beyond the 'career toolkit' (e.g. Bridgstock, 2009) to include career management, academic and disciplinary knowledge, personal attributes and development and an intersection of any and all of these (Brent et al., 2017).

Development of PLUS templates and presentation of the program in the PebblePad environment are now nearing completion. Next steps will include an overt and explicit attempt to replicate the approach undertaken by the School of Engineering and Built Environment in the Bachelor of Engineering in other programs within the Griffith Sciences Group. Formal evaluation of the impact of PLUS will also be included in the next phase. This will include an evaluation of the extent to which students involved in the curricular activity perceive the relationship between tasks (from first to final year) and the extent to which the program is engaging and beneficial for students as an extra-curricular option. Academic staff perceptions of the barriers, challenges and opportunities to embed and assess employability will also be explored.

\section{References}

Barrett, H. (2010). Balancing the two faces of ePortfolios. Educação, Formação \& Tecnologias, 3(1), 6-14.

Bennett, D., Richardson, S., \& MacKinnon, P. (2016). Enacting strategies for graduate employability: How universities can best support students to develop generic skills. Sydney, Australia: Australian Government Office for Learning and Teaching.

Brent, G., Sanger, G., \& John, R. (2017). A framework to embed employability initiatives in undergraduate science, technology, engineering and maths programs. In R. G. Walker \& S. B. Bedford (Eds.), Research and development in higher education: Curriculum transformation (Vol. 40, pp. 38-49). Sydney, Australia. 
Bridgstock, R. (2009). The graduate attributes we've overlooked: Enhancing graduate employability through career management skills. Higher Education Research \& Development, 28(1), 31-44.

Dacre Pool, L., \& Sewell, P. (2007). The key to employability: Developing a practical model of graduate employability. Education and Training, 49(4), 277-289. https://doi.org/10.1108/ 00400910710754435.

Finkel, A. (2016, August 29). Time to change our university graduate expectations by degrees. Providers remake their operating models in the era of mass tertiary education. The Australian. Retrieved November 11, 2018, from http://www.theaustralian.com. au/opinion/time-to-change-our-university-graduate-expectations-by-degrees/news-story/ 8438b778cad5f7ab593697f3712acabf.

Foundation for Young Australians. (2017). The new work smarts: Thriving in the new work order. Retrieved November 11, 2018, from https://www.fya.org.au/wp-content/uploads/2017/07/FYA_ TheNewWorkSmarts_July2017.pdf.

Greenbank, P. (2014). Competing in the graduate labour market: Student perspectives on (not) participating in extra-curricular activities. Journal of Teaching and Learning for Graduate Employability, 5(1), 63-79. https://doi.org/10.21153/jtlge2014vol5no1art568.

Holmes, L. (2001). Reconsidering graduate employability: The 'graduate identity' approach. Quality in Higher Education, 7(2), 111-119. https://doi.org/10.1080/13538320120060006.

Jackson, D. (2014). Testing a model of undergraduate competence in employability skills and its implications for stakeholders. Journal of Education and Work, 27(2), 220-242. https://doi.org/ 10.1080/13639080.2012.718750.

Johnson, L., Adams Becker, S., Estrada, V., \& Freeman, A. (2014). NMC horizon report: 2014 higher (Education ed.). Austin, Texas: The New Media Consortium.

Kinash, S., Crane, L., Judd, M. M., Mitchell, K., McLean, M., Knight, C., \& Schulz, M. (2015). Supporting graduate employability from generalist disciplines through employer and private institution collaboration. Sydney: Australian Government Office for Learning and Teaching.

Lizzio, A. (2012). The student lifecycle: An integrative framework for guiding practice. Brisbane, Australia: Griffith University.

Monks, K., Conway, E., \& Dhuigneain, M. N. (2006). Integrating personal development and career planning: The outcomes for first year undergraduate learning. Active Learning in Higher Education, 7(1), 73-86. https://doi.org/10.1177/1469787406063216.

Muldoon, R. (2009). Recognizing the enhancement of graduate attributes and employability through part-time work while at university. Active Learning in Higher Education, 10(3), 237-252. https:// doi.org/10.1177/1469787409343189.

Pegg, A., Waldock, J., Hendy-Isaac, S., \& Lawton, R. (2012). Pedagogy for employability. York, United Kingdom: Higher Education Academy.

PricewaterhouseCoopers. (2015). A smart move: Future-proofing Australia's workforce by growing skills in Science, Technology, Engineering and Maths (STEM). Australia: Author.

Prinsley, R., \& Baranyai, K. (2015). STEM trained and job ready. Office of the Chief Scientist. Occasional Paper Series (Issue 12, August, 2015).

Queensland Government Department of Education, Training and the Arts. (n.d.). Towards a 10year plan for science, technology, engineering and mathematics (STEM) education and skills in Queensland. Retrieved November 14, 2018, from http://education.qld.gov.au/projects/stemplan/ docs/stem-discussion-paper.pdf.

Rich, J. (2016). Employability: degrees of value. I worked hard to get where I am today (An unemployed graduate with $£ 50,000$ of debt). HEPI Occasional Paper 12.

Rogers, C., Fisher, A., Walker, L., Balmer, A., Brennan, K., Redmond, P., Whitmore, A., \& Freeman, L. (2016). Academic advising for employability toolkit. Higher Education Academy. Retrieved November 11, 2018, from https://www.heacademy.ac.uk/resource/academic-advisingemployability-toolkit.

The Australian Industry Group. (2015). Progressing STEM Skills in Australia. Retrieved November 14, 2018, from http://cdn.aigroup.com.au/Reports/2015/14571_STEM_Skills_Report_Final_-. pdf. 
Thompson, L. J., Clark, G., Walker, M., \& Whyatt, J. D. (2013). 'It's just like an extra string to your bow': Exploring higher education students' perceptions and experiences of extracurricular activity and employability. Active Learning in Higher Education, 14(2), 135-147.

Wingate, U. (2006). Doing away with 'study skills'. Teaching in Higher Education, 11(4), 457-469. https://doi.org/10.1080/13562510600874268.

Wharton, C. Y., \& Horrocks, J. (2015). Students' perception of employability within their degree programme: Highlighting the disparity between what academics believe is included and the student experience. In Enhancement and Innovation in Higher Education.

Yorke, M. (2006). Employability in higher education: What it is-what it is not. Learning and Employability Series, 1. York, United Kingdom: Higher Education Academy.

Yorke, M., \& Knight, P. (2006). Embedding employability into the curriculum (Vol. 3). York, United Kingdom: Higher Education Academy.

Gayle Brent is a Learning and Teaching Consultant (Curriculum) in the Griffith Sciences. Gayle's specialist area of interest is developing and implementing strategies to enhance staff and student understanding of employability, in both curricular and extra-curricular contexts. Gayle has a unique perspective on the challenges students experience at various stages of the student life cycle, having worked in roles that span outreach, orientation and transition, career development and alumni engagement. She applies innovative, creative solutions to enhance student engagement with employability-based learning. 